\title{
Regional differences of densitometric and geometric parameters of the third metacarpal bone in coldblood horses - PQCT study
}

\author{
Małgorzata Dzierzęcka ${ }^{1}$, Maciej Jaworski ${ }^{2}$, Halina Purzyc ${ }^{3}$, Karolina Barszcz $^{1}$ \\ ${ }^{1}$ Department of Morphological Science, Faculty of Veterinary Medicine, \\ Warsaw University of Life Sciences, 02-776 Warsaw, Poland \\ ${ }^{2}$ Department of Biochemistry, Radioimmunology, and Experimental Medicine, \\ The Children's Memorial Health Institute, 04-730 Warsaw, Poland \\ ${ }^{3}$ Department of Animal Physiology and Biostructure, Faculty of Veterinary Medicine, \\ Wroclaw University of Environmental and Life Sciences, 51-631 Wroclaw, Poland \\ malgorzatadzierzecka@wp.pl
}

Received: November 11, 2016

Accepted: March 10, 2017

\begin{abstract}
Introduction: The aim of the study was to analyse selected densitometric and geometric parameters in the third metacarpal bone along the long axis in horses. The densitometric parameters included the cortical and trabecular bone mineral density, while the geometric parameters included the cortical, trabecular, and total areas, strength strain index X, strength strain index $\mathrm{Y}$, and the polar strength strain index. Material and Methods: The parameters were analysed using eight sections from $10 \%$ to $80 \%$ of the length of the bone. Peripheral quantitative computed tomography was used in the study. Statistical analysis was carried out using the Friedman analysis of variance and post-hoc tests. Results: The proximal metaphyseal region showed the highest predicted resistance to bone fractures in the transverse (back-front) plane, the distal metaphyseal region had the highest predicted resistance to transverse and torsional fractures in the transverse (side-side) plane. The cross-sectional area and the shape of the cross-section of the cortical bone of the MCIII had the highest coefficient of variation. The density of the cortical bone was least variable. Conclusions: The cortical area and cortical bone mineral density assumed the highest values in the diaphyseal region, while the highest total area, trabecular area and trabecular bone mineral density values were obtained in the metaphyseal proximal and distal region.
\end{abstract}

Keywords: horses, bone parameters, pQCT, third metacarpal bone.

\section{Introduction}

Numerous attempts have been made to differentiate densitometric and geometric parameters of long bones. Initially, studies focused on differentiating the parameters based on the limb section - the shoulder girdle, epiphysis of the humerus and femur, zeugopodium, and autopodium $(3,25,26,27)$. Those studies showed that the parameters from the distal limb segments differed significantly from the parameters from the proximal limb segments. In the limb bones in cursorial mammals, there is a gradual decrease in the bone mineral content from the proximal bones (humerus) to the distal bones (phalanges), where the bone mineral content (BMC) value is the lowest $(24,26$, 27). A similar study was carried out in the Rocky Mountain mule deer and showed that the osteon population density (no. $/ \mathrm{mm}^{2}$ ) gradually increased in the direction of the peripheral bone segments and was the highest in the phalanges, where the values were up to five times higher than in the humerus (24). The same authors found that new remodelling events were most often found in proximal bone segments. Bones undergoing intense remodelling were found to be less resistant to forces than bones with a physiological osteon arrangement. There is little cortical remodelling and secondary osteonal bone in the distal limb segments, and the relative amount of remodelled cortex increases 
proximally. Since the distal limb segments are more prone to microfractures, they adapt in order to increase the fatigue life (24).

Bone parameters have been differentiated based on limb segments. This is due to the fact that bones in individual segments show a certain adaptation to improve the material and structural properties of the limb segments subjected to different types of forces (3). Long bones in mammals have variable parameters depending on the limb segment they are located in. Furthermore, there may be characteristic differences in the geometric and densitometric parameters within one bone. This variation depends on the place where the measurements are taken $(8,13,14)$.

The densitometric and geometric properties of a bone are characteristic at various levels. Such information may be utilised practically, for example during surgical procedures. Given the structural and densitometric properties of a given bone at a particular location, it is possible to predict and monitor the likelihood of injury in a given individual. The current state of knowledge concerning the differentiation of long bone parameters depending on the site of the measurement in humans has been used in several areas, for example, to determine the optimal location of osteosynthesis. Therefore, the data concerning the distribution of the densitometric and geometric parameters in limb bones may be applied during surgical procedures $(7,16,20)$.

There are very few studies concerning the diversity of the densitometric and geometric bone properties in horses depending on the measurement location. Such studies were carried out on the radius and tibia $(10,17)$ and hock $(4,5)$. The third metacarpal bone in horses was also subjected to a densitometric analysis (30).

Due to the limitations of the densitometric analysis, which are caused by the inability to assess the bone tissue microstructure, we carried out an analysis to differentiate densitometric and geometric parameters in the third metacarpal bone (MCIII) in horses depending on the site of measurement using peripheral quantitative computed tomography (pQCT). The advantage of the pQCT method is that it enables performing not only densitometric measurements, but also measurements of actual bone density and 3D measurements, known as geometric parameters, which determine the strength of the bone. The bones were analysed in eight sections along their long axes between $10 \%$ and $80 \%$ of their length. The study was carried out on the MCIII bones as these bones are considered to be the horse bones most susceptible to injury $(18,19)$.

\section{Material and Methods}

The study was performed on the left MCIII bone of 21 coldblood horses from Poland, mainly used as draft horses (6). The animals came from private farms and were slaughtered in the Rawicz abattoir for reasons unrelated to musculoskeletal disease. Their mean body mass was $520 \pm 75 \mathrm{~kg}$, and the animals were from 3 to 27 years of age. The limbs and metacarpal bones were obtained from randomly selected horses.

The bones were stripped of soft tissues leaving the periosteum. They were then tightly packed in plastic bags, labelled, and stored at $-22^{\circ} \mathrm{C}$. The length of the MCIII measured from the proximal end to the articular surface, omitting the crest-like ridge, was determined using a digital calliper. During the CT analysis, the III metacarpal bone was placed so that the crest was positioned vertically, and the dorsal surface of the bone was directed upwards.

The analysis of the densitometric and geometric parameters of the bones was carried out using a singlerow Stratec XCT 2000L peripheral CT scanner (Stratec Medizintechnik, Germany). The measurements were obtained during a five-month period. During this time, the scanner underwent quality control in accordance with the manufacturer's instructions. The measurement error was calculated using a phantom model and amounted to $0.22 \%$ for the density of the entire bone section, $0.29 \%$ for the trabecular density, and $0.24 \%$ for the compact bone density. The following densitometric parameters were analysed: cortical bone mineral density (CRT BMD) $\mathrm{mg} / \mathrm{cm}^{3}$ - the mineral density of the cortical bone at the site of measurement, the trabecular bone mineral density (TRAB_BMD) $\mathrm{mg} / \mathrm{cm}^{3}-$ the mineral density of the trabecular bone at the measurement site, and the following geometric parameters: cortical bone area (CRT_A) $\mathrm{mm}^{2}-$ the surface area of the cortical bone at the measurement site, the trabecular bone area (TRAB_A) $\mathrm{mm}^{2}$ - the surface area of the trabecular bone at the measurement site, the total area (TOT_A) $\mathrm{mm}^{2}$ - the total area of the bone at the measurement site. The section modulus was calculated for three types of fractures. The strength strain index X (SSI_X) $\mathrm{mm}^{3}$ - a parameter of the fracture resistance of bones in the transverse (forward-backward) plane, strength strain index Y (SSI_Y) $\mathrm{mm}^{3}$ a parameter of the fracture resistance of bones in the transverse (side-side) plane and the polar strength strain index (SSI_P) $\mathrm{mm}^{3}$ - a parameter of the expected fracture resistance of bones to torsional fractures.

The tomographic analysis of the III metacarpal bone was carried out at 10\%, 20\%, 30\%, 40\%, 50\%, $60 \%, 70 \%$, and $80 \%$ of the length of the bone to determine CRT_A, CRT_BMD, SSI_X, SSI_Y, SSI_P, TOT_A, and at $10 \%, 20 \%, 60 \%, 70 \%$, and $80 \%$ for the parameters of the trabecular bone. The survey studies revealed that there was no trabecular bone at the $30 \%$, $40 \%$, and $50 \%$ sections. A $0.575 \mathrm{~mm}^{3}$ voxel was used, and measurements were taken using a scanning speed of $30 \mathrm{~mm} / \mathrm{s}$. The algorithm threshold, which differentiated cortical and trabecular bone, was set at $711 \mathrm{mg} / \mathrm{cm}^{3}$ for all the parameters, except for SSI_X, SSI_Y, SSI_P, where the threshold was set at $480 \mathrm{mg} / \mathrm{cm}^{3}$.

The normality of data distribution was assessed using the Shapiro-Wilk test. The parameters were not distributed normally, and the Friedman analysis of variance (ANOVA) and post-hoc tests were carried out. 
The statistically significant differences between parameters at the different measurement sites in the left MCIII are presented in Table 1 and box-plots. The whiskers represent the minimal and maximal values of each parameter. The size of the box represents the variability, which occurred in 50\% of the animals (25\%-75\% range). All calculations were performed using the Statistica 10 PL (StatSoft, USA) software. The significance level was set at $\mathrm{P}<0.05$.

\section{Results}

The values of the measured densitometric and geometric parameters of the left III metacarpal bones in cold-blooded horses, analysed at sections from $10 \%$ to $80 \%$ of the length of the bone, are presented in Figs $1-10$. The results of the ANOVA analysis are presented in Figures and Table 1. The figures illustrate the values of the parameters depending on the measurement site. The differences between parameters and ANOVA p-values for selected groups (post-hoc tests) are presented in Table 1.

The CRT_A $\left(\mathrm{mm}^{2}\right)$ values did not show any statistically significant differences at $10 \%$ and $20 \%$ of the length of the III metacarpal bone. At $30 \%$ of the bone length, the parameter increased significantly compared to the value obtained at the $20 \%$ bone length. The difference in the CRT_A $\left(\mathrm{mm}^{2}\right)$ values obtained at $30 \%$ and $10 \%$ was significant. CRT_A reached the highest values at $30 \%, 40 \%$, and $50 \%$ of the diaphyseal length, and these values were significantly different from the values obtained at the remaining sites (Table 1, Fig. 1). The CRT_A values did not differ significantly between the $30 \%$ and $50 \%$ diaphyseal length sites. At the $60 \%$ diaphyseal length, the CRT_A value was significantly lower than the values obtained at $30 \%$ and $40 \%$ of the bone length. This parameter was significantly lower at $70 \%$ and $80 \%$ of the diaphyseal length compared to the maximal values obtained between $30 \%$ and $50 \%$ of the bone length. There were no statistical differences in the CRT_A values obtained at $70 \%$ and $80 \%$ of the bone length. The highest CRT_A values were obtained between $30 \%$ and $50 \%$ of the bone length (Fig. 1). The highest median value for this parameter was recorded at $50 \%$ of the bone length, and it equalled $758.8 \mathrm{~mm}^{2}$. The lowest median value $\left(525.0 \mathrm{~mm}^{2}\right)$ was recorded at $80 \%$ of the bone length. The highest interquartile ranges were noted at 50\%, 40\%, and 30\% (145.7 $\mathrm{mm}^{2}, 131.2 \mathrm{~mm}^{2}$ and $118.5 \mathrm{~mm}^{2}$, respectively).

The CRT_BMD $\left(\mathrm{mg} / \mathrm{cm}^{3}\right)$ value at $10 \%$ of the bone length of the III metacarpal bone was significantly lower than the value obtained at $20 \%$. The median values were $1120.0 \mathrm{mg} / \mathrm{cm}^{3}$ and $1193.9 \mathrm{mg} / \mathrm{cm}^{3}$, respectively. The value of CRT_BMD was significantly lower at $10 \%$ of the bone length compared to the values recorded at the remaining sites except $80 \%$. At $80 \%$ of the diaphyseal length, the median value decreased to $1047.9 \mathrm{mg} / \mathrm{cm}^{3}$. The highest CRT_BMD values, which were $1217.70 \mathrm{mg} / \mathrm{cm}^{3}, 1222.3 \mathrm{mg} / \mathrm{cm}^{3}, 1231.2 \mathrm{mg} / \mathrm{cm}^{3}$ and were obtained at $40 \%, 50 \%$, and $60 \%$ of the diaphyseal length respectively, did not differ significantly among one another (Table 1, Fig. 2). The CRT_BMD value decreased significantly at $70 \%$ of the bone length and was significantly smaller than the highest obtained values. The CRT_BMD value obtained at $80 \%$ of the bone length was significantly lower than the values obtained from $30 \%$ to $60 \%$ of the bone length (Fig. 2). The highest interquartile ranges were recorded at $20 \%$ and $80 \%$ and amounted to $45.7 \mathrm{mg} / \mathrm{cm}^{3}$ and 45.9 $\mathrm{mg} / \mathrm{cm}^{3}$, respectively.

The highest SSI_X $\left(\mathrm{mm}^{3}\right)$ median $\left(3386.1 \mathrm{~mm}^{3}\right)$ was recorded at $10 \%$ of the bone length. This value was significantly greater than the values obtained at the remaining sites in the III metacarpal bone. The SSI_X values obtained from $20 \%$ to $70 \%$ of the bone length did not differ among one another, while the value $\left(2673.5 \mathrm{~mm}^{3}\right)$ recorded at $80 \%$ of the bone length was the lowest of all the recorded values (Table 1, Fig. 3). The highest interquartile ranges were obtained at $10 \%, 60 \%$, and $70 \%$ and amounted to $1209.3 \mathrm{~mm}^{3}, 1296.7 \mathrm{~mm}^{3}$ and $1205.5 \mathrm{~mm}^{3}$.

The SSI_Y $\left(\mathrm{mm}^{3}\right)$ values obtained at sites from $10 \%$ to $60 \%$ of the length of the left III metacarpal bone differed significantly. The median value gradually increased until $70 \%$ of the bone length $\left(5010.4 \mathrm{~mm}^{3}\right)$. The highest SSI_Y median value, which was $5192.2 \mathrm{~mm}^{3}$, was noted at $80 \%$ of the bone length. This value was significantly higher than the value obtained at all the remaining sites apart from $70 \%$ of the bone length (Table 1, Fig. 4).

The highest quartiles, which were $27.02 \mathrm{~mm}^{3}$, $27.23 \mathrm{~mm}^{3}$, and $28.46 \mathrm{~mm}^{3}$, were obtained at $40 \%, 50 \%$, and $80 \%$ of the bone length, respectively. The SSI_P $\left(\mathrm{mm}^{3}\right)$ median values at $10 \%, 20 \%, 30 \%, 40 \%$, and $80 \%$ of the bone length did not differ statistically among one another and ranged from $6461.7 \mathrm{~mm}^{3}$ to $6616.4 \mathrm{~mm}^{3}$. The highest SSI_P value was obtained at $70 \%$ of the bone length $6914.6 \mathrm{~mm}^{3}$ (Table 1, Fig. 5).

The highest quartiles were recorded at $60 \%$ and $80 \%$ of the bone length and amounted to $2653.5 \mathrm{~mm}^{3}$ and $2748.3 \mathrm{~mm}^{3}$. The III left metacarpal bones had the highest TOT_A mm ${ }^{2}$ values, at $10 \%, 70 \%$, and $80 \%$ of the diaphyseal length, which were $1199.0 \mathrm{~mm}^{2}, 1047.8 \mathrm{~mm}^{2}$, and $1121.8 \mathrm{~mm}^{2}$, respectively. These values did not differ significantly. The TOT_A values obtained from $20 \%$ to $60 \%$ of the diaphyseal length were significantly lower than the highest values. The lowest TOT_A median value was obtained at $40 \%$ of the diaphyseal length $909.0 \mathrm{~mm}^{2}$ (Table 1, Fig. 6). The highest TOT_A $\left(\mathrm{mm}^{2}\right)$ quartiles were recorded at $10 \%$ and $80 \%$ and amounted to $244.2 \mathrm{~mm}^{2}$ and $272.2 \mathrm{~mm}^{2}$.

Similarly to TOT_A mm² results, the highest third left metacarpal bone TRAB_A $\mathrm{mm}^{2}$ median values were obtained at $10 \%, 70 \%$, and $80 \%$ of the bone length. The values were $377.0 \mathrm{~mm}^{2}, 295.8 \mathrm{~mm}^{2}$, and $364.5 \mathrm{~mm}^{2}$, respectively. These values were statistically higher than those obtained between $20 \%$ and $60 \%$ of the bone length. The highest TRAB_A interquartile ranges were obtained at $10 \%$ and $80 \%$ and amounted to $135.2 \mathrm{~mm}^{2}$ and $144.2 \mathrm{~mm}^{2}$ (Table 1, Fig. 7). 
Table 1. The post-hoc analysis of densitometric and geometric parameters values of the left third metacarpal bone $(n=21)$ depending on the measurement section with statistically significant differences

\begin{tabular}{|c|c|c|c|c|c|c|c|c|}
\hline \multirow{2}{*}{$\begin{array}{l}\text { Densitometric } \\
\text { and geometric } \\
\text { parameters }(\%)\end{array}$} & \multicolumn{8}{|c|}{ Measurement section of bone $(\%)$} \\
\hline & & 20 & 30 & 40 & 50 & 60 & 70 & 80 \\
\hline \multirow{8}{*}{$\begin{array}{l}\text { Cortical } \\
\text { bone area } \\
\text { (CRT_A) }\end{array}$} & 10 & NS & $* *$ & ** & $* *$ & NS & NS & NS \\
\hline & 20 & - & $*$ & $*$ & NS & NS & NS & $* *$ \\
\hline & 30 & & - & NS & NS & $*$ & $* *$ & $* *$ \\
\hline & 40 & & & - & NS & $*$ & $* *$ & $* *$ \\
\hline & 50 & & & & - & NS & $* *$ & $* *$ \\
\hline & 60 & & & & & - & NS & $* *$ \\
\hline & 70 & & & & & & - & NS \\
\hline & 80 & & & & & & & - \\
\hline \multirow{8}{*}{$\begin{array}{l}\text { Cortical bone } \\
\text { mineral density } \\
(\mathrm{CRT} B \mathrm{BMD})\end{array}$} & 10 & $*$ & $* *$ & $* *$ & $* *$ & $* *$ & $* *$ & NS \\
\hline & 20 & - & NS & $* *$ & $* *$ & $* *$ & NS & NS \\
\hline & 30 & & - & NS & NS & NS & NS & $* *$ \\
\hline & 40 & & & - & NS & NS & $*$ & $* *$ \\
\hline & 50 & & & & - & NS & $* *$ & $* *$ \\
\hline & 60 & & & & & - & $*$ & $* *$ \\
\hline & 70 & & & & & & - & NS \\
\hline & 80 & & & & & & & - \\
\hline \multirow{8}{*}{$\begin{array}{l}\text { Strength strain } \\
\text { index X } \\
\text { (SSI_X) }\end{array}$} & 10 & ** & *** & $* *$ & * & $* *$ & ** & ** \\
\hline & 20 & - & NS & NS & NS & NS & NS & $*$ \\
\hline & 30 & & - & NS & NS & NS & NS & $*$ \\
\hline & 40 & & & - & NS & NS & NS & $* *$ \\
\hline & 50 & & & & - & NS & NS & $* *$ \\
\hline & 60 & & & & & - & NS & $* *$ \\
\hline & 70 & & & & & & - & $*$ \\
\hline & 80 & & & & & & & - \\
\hline \multirow{8}{*}{$\begin{array}{l}\text { Strength strain } \\
\text { index Y } \\
\text { (SSI_Y) }\end{array}$} & 10 & NS & NS & $\mathrm{NS}$ & NS & NS & $\mathrm{NS}$ & *** \\
\hline & 20 & - & NS & NS & NS & NS & NS & $* *$ \\
\hline & 30 & & - & NS & NS & NS & NS & $* *$ \\
\hline & 40 & & & - & NS & NS & $*$ & $* *$ \\
\hline & 50 & & & & - & NS & NS & $* *$ \\
\hline & 60 & & & & & - & NS & $* *$ \\
\hline & 70 & & & & & & - & NS \\
\hline & 80 & & & & & & & - \\
\hline \multirow{8}{*}{$\begin{array}{l}\text { Polar strength } \\
\text { strain index } \\
\text { (SSI_P) }\end{array}$} & 10 & NS & NS & $\mathrm{NS}$ & $*$ & NS & NS & NS \\
\hline & 20 & - & NS & NS & $* *$ & $* *$ & $*$ & NS \\
\hline & 30 & & - & NS & $* *$ & NS & NS & NS \\
\hline & 40 & & & - & NS & NS & NS & NS \\
\hline & 50 & & & & - & NS & NS & $* *$ \\
\hline & 60 & & & & & - & NS & NS \\
\hline & 70 & & & & & & - & NS \\
\hline & 80 & & & & & & & - \\
\hline \multirow{8}{*}{$\begin{array}{l}\text { Total area } \\
\text { (TOT_A) }\end{array}$} & 10 & $* *$ & $* *$ & $* *$ & $* *$ & $* *$ & NS & NS \\
\hline & 20 & - & NS & NS & NS & NS & NS & $*$ \\
\hline & 30 & & - & NS & NS & NS & $* *$ & $* *$ \\
\hline & 40 & & & - & NS & NS & $* *$ & $* *$ \\
\hline & 50 & & & & - & NS & $* *$ & $* *$ \\
\hline & 60 & & & & & - & NS & $* *$ \\
\hline & 70 & & & & & & - & NS \\
\hline & 80 & & & & & & & - \\
\hline \multirow{5}{*}{$\begin{array}{l}\text { Trabecular } \\
\text { bone area } \\
\text { (TRAB_A) }\end{array}$} & 10 & $* *$ & & & & $* *$ & NS & NS \\
\hline & 20 & - & & & & NS & $*$ & $* *$ \\
\hline & 60 & & & & & - & $* *$ & $* *$ \\
\hline & 70 & & & & & & - & NS \\
\hline & 80 & & & & & & & - \\
\hline \multirow{5}{*}{$\begin{array}{l}\text { Trabecular bone } \\
\text { mineral density } \\
\text { (TRAB_BMD) }\end{array}$} & 10 & ** & & & & ** & $\mathrm{NS}$ & $\mathrm{NS}$ \\
\hline & 20 & - & & & & NS & $* *$ & $* *$ \\
\hline & 60 & & & & & - & NS & $* *$ \\
\hline & 70 & & & & & & - & $* *$ \\
\hline & 80 & & & & & & & - \\
\hline
\end{tabular}




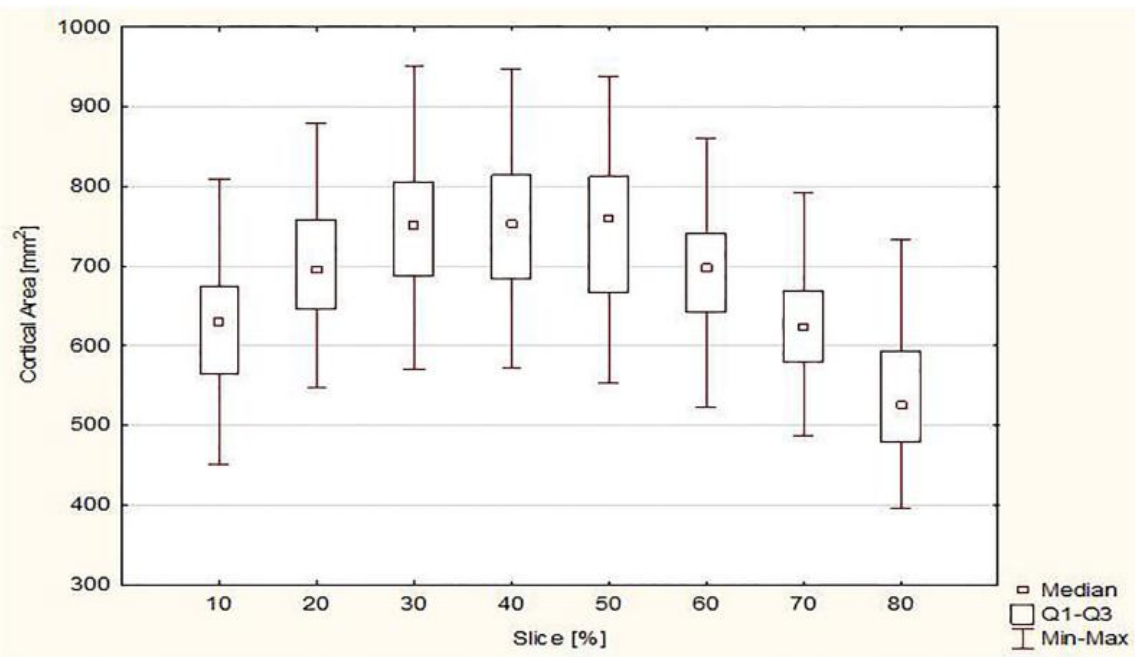

Fig. 1. The cortical bone area (CRT_A) values of the left third metacarpal bone $(n=21)$ in coldblood horses from Poland depending on the measurement section along the long axis (\%). Friedman's ANOVA (overall $\mathrm{P}<0.0001$ )

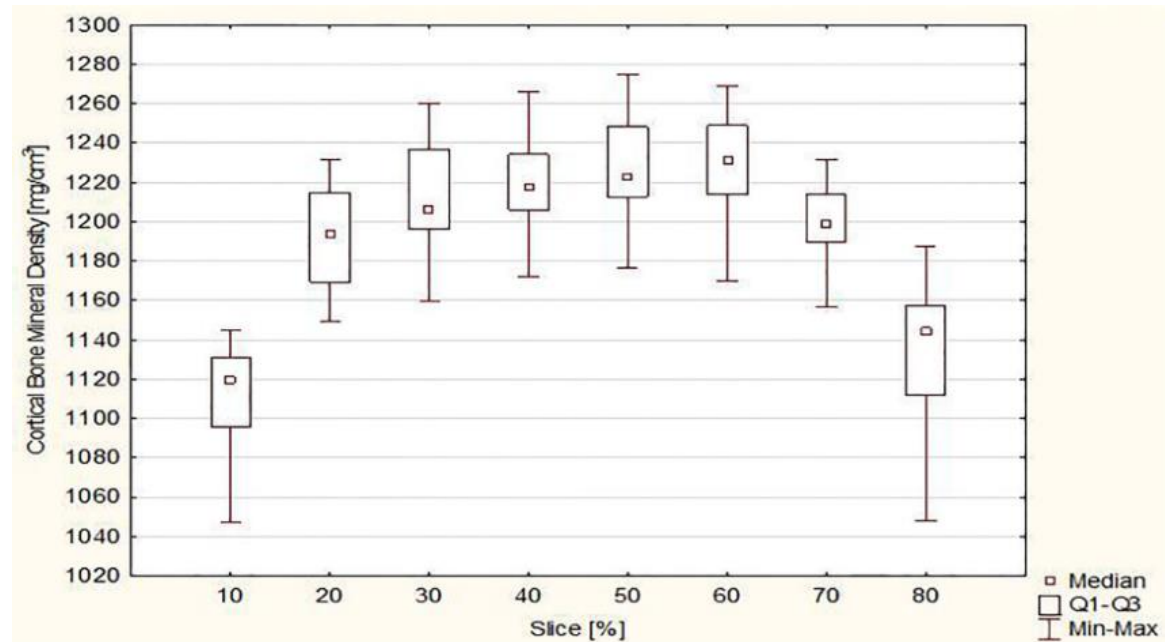

Fig. 2. The cortical bone mineral density (CRT_BMD) values of the left third metacarpal bone $(\mathrm{n}=21)$ in coldblood horses from Poland depending on the measurement section along the long axis (\%). Friedman's ANOVA (overall $\mathrm{P}<0.0001$ )



Fig. 3. The strength strain index X (SSI_X) values of the left third metacarpal bone $(n=21)$ in coldblood horses from Poland depending on the measurement section along the long axis (\%). Friedman's ANOVA (overall $\mathrm{P}<0.0001$ ) 


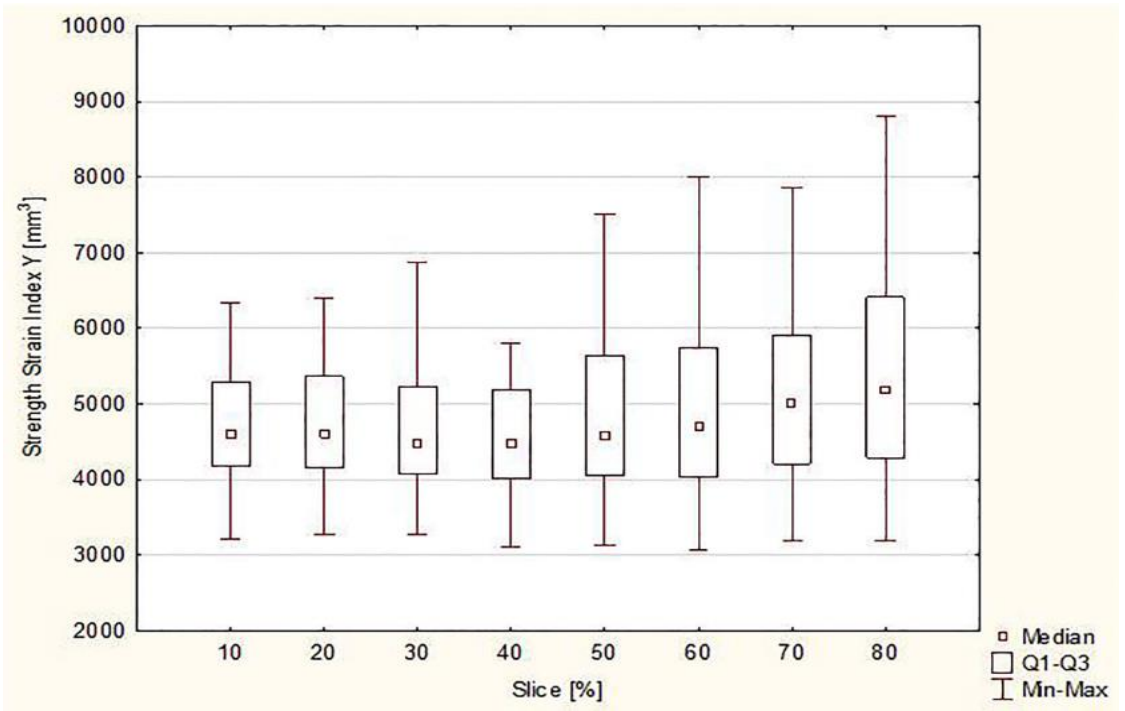

Fig. 4. The strength strain index Y (SSI_Y) values of the left third metacarpal $(n=21)$ in coldblood horses from Poland depending on the measurement section along the long axis (\%). Friedman's ANOVA (overall $\mathrm{P}<0.0001$ )

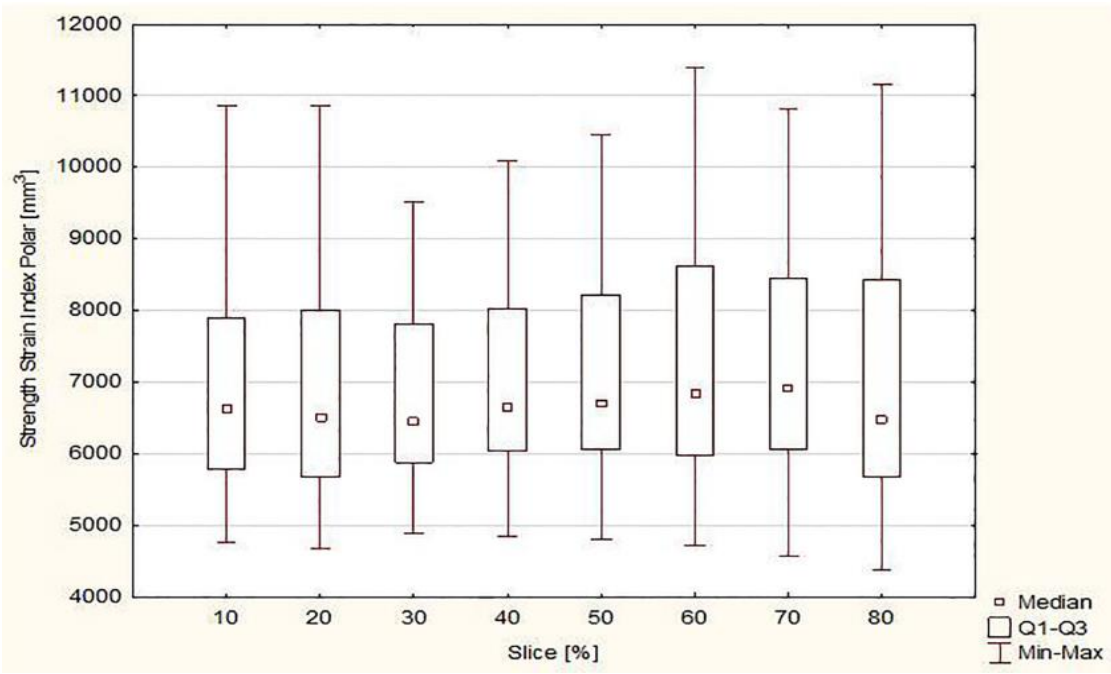

Fig. 5. The polar strength strain index (SSI_P) values of the left third metacarpal bone $(\mathrm{n}=21)$ in coldblood horses from Poland depending on the measurement section along the long axis (\%). Friedman's ANOVA (overall $\mathrm{P}<0.0001$ )

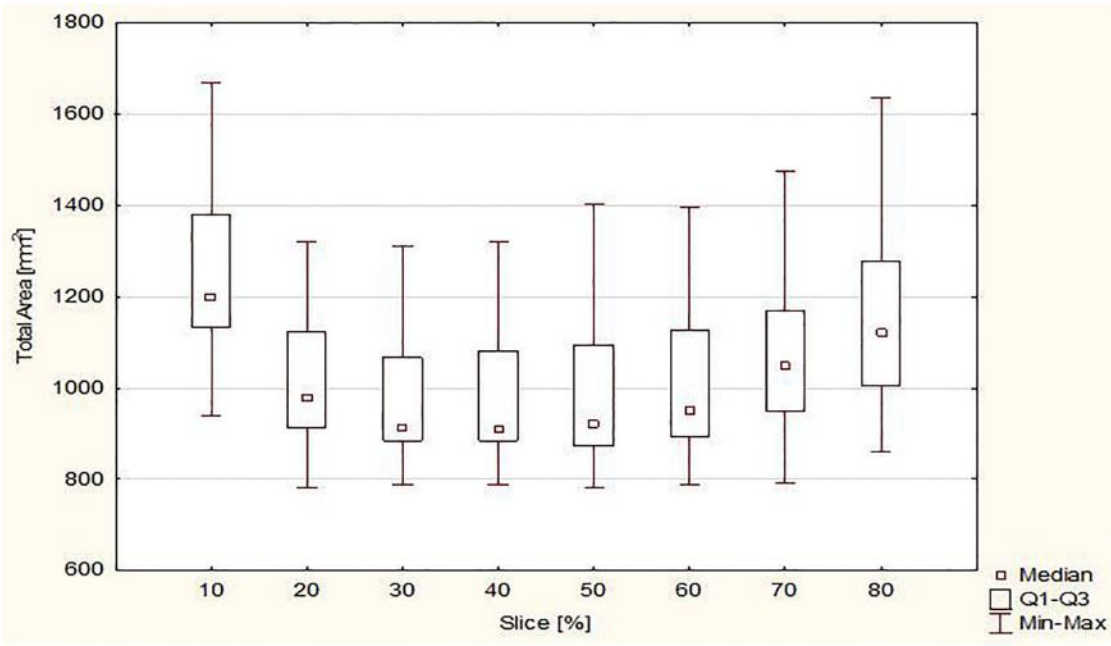

Fig. 6. The total area (TOT_A) values of the left third metacarpal bone in $(n=21)$ in coldblood horses from Poland depending on the measurement section along the long axis (\%). Friedman's ANOVA (overall $\mathrm{P}<0.0001$ ) 


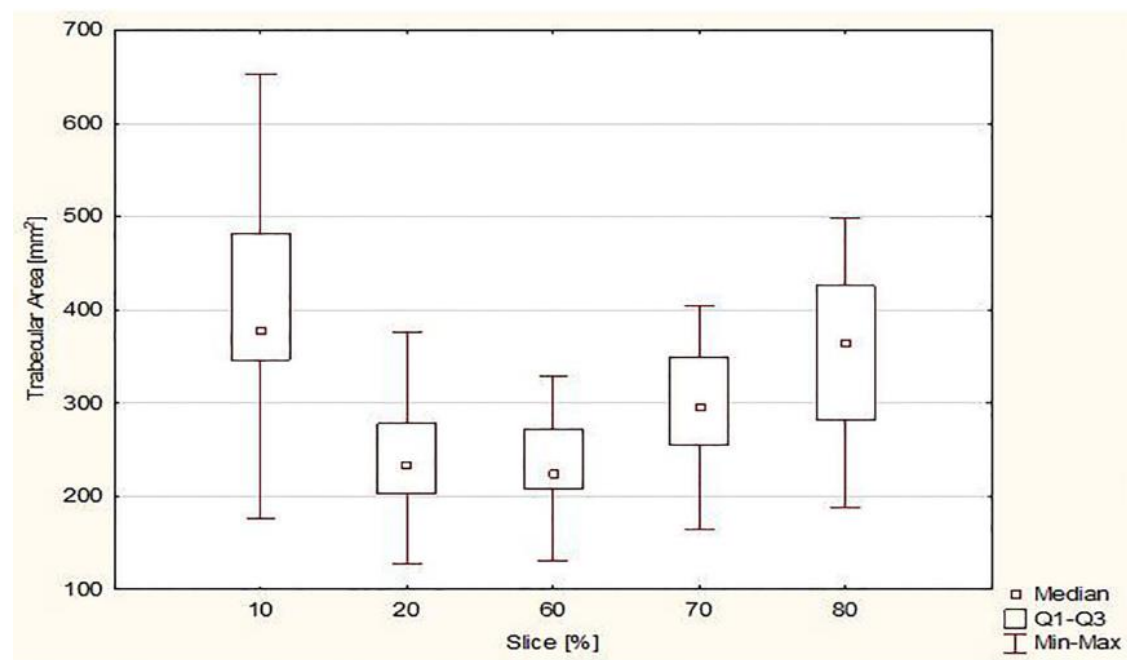

Fig. 7. The trabecular bone area (TRAB_A) values of the left third metacarpal bone in $(n=21)$ in coldblood horses from Poland depending on the measurement section along the long axis (\%). Friedman's ANOVA (overall $\mathrm{P}<0.0001$ )

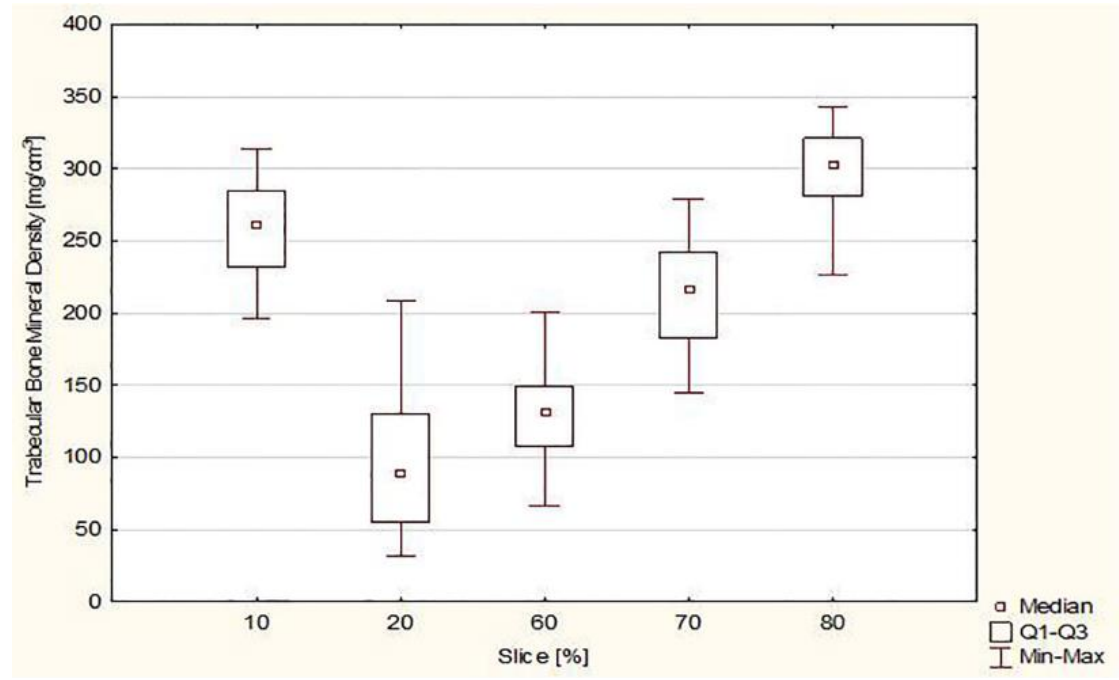

Fig. 8. The trabecular bone mineral density (TRAB_BMD) values of the left third metacarpal bone $(\mathrm{n}=21)$ in coldblood horses from Poland depending on the measurement section along the long axis (\%). Friedman's ANOVA (overall P < 0.0001)

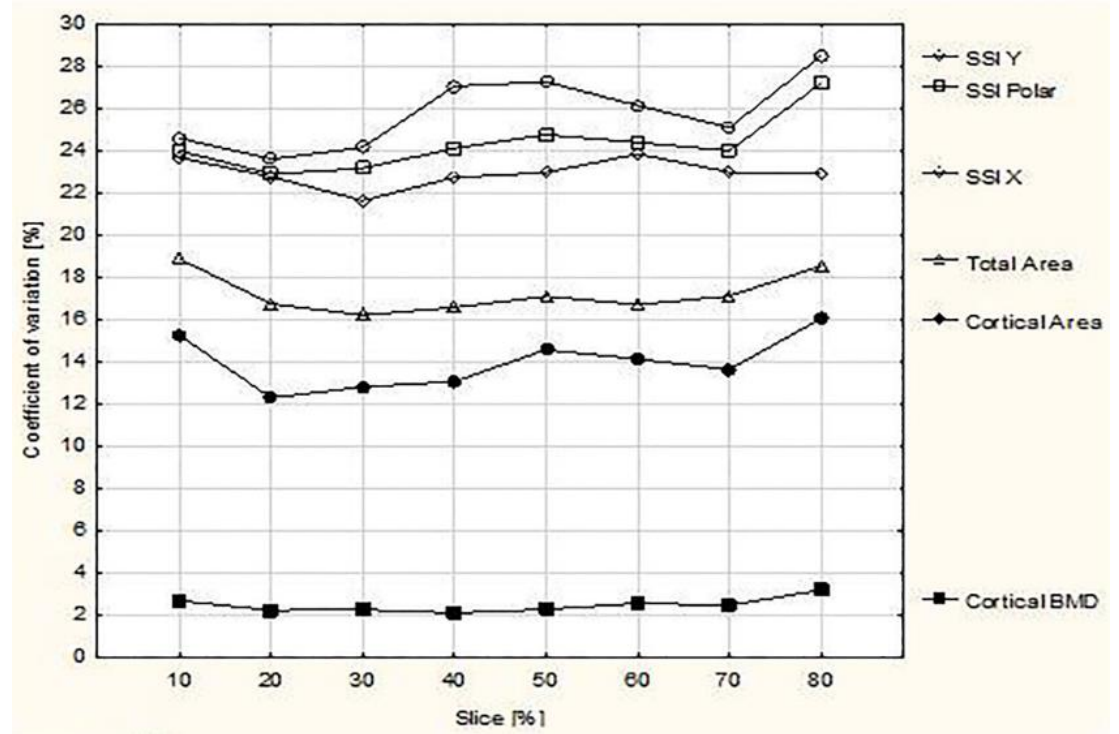

Fig. 9. The coefficients of variation CV for SSI_Y, SSI_P, SSI_X, TOT_A, CRT_A, and CRT_BMD $(\%)$ 


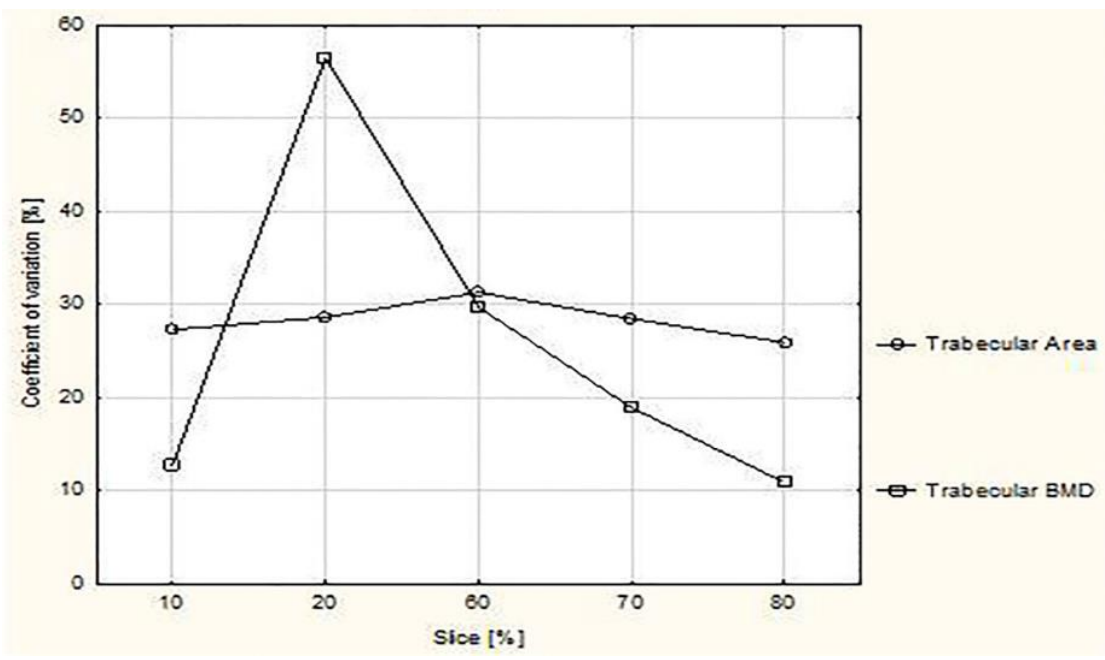

Fig. 10. The coefficients of variation $C V$ for TRAB_BMD and TRAB_A (\%)

The TRAB_BMD $\left(\mathrm{mg} / \mathrm{cm}^{3}\right)$ values $\left(261.5 \mathrm{mg} / \mathrm{cm}^{3}\right.$, $216.8 \mathrm{mg} / \mathrm{cm}^{3}$, and $303.1 \mathrm{mg} / \mathrm{cm}^{3}$ ), measured at $10 \%$, $70 \%$, and $80 \%$ of the bone length, were significantly larger than those obtained at the other lengths of the III metacarpal bone. The highest TRAB_BMD interquartile ranges were found at $20 \%$ of the bone length $(74.9$ $\mathrm{mg} / \mathrm{cm}^{3}$ ) (Table 1, Fig. 8.).

The coefficients of variation of SSI_Y, SSI_P, SSI_X, TOT_A, CRT_A, and CRT_BMD are presented in Fig. 9, while the coefficients of variation of TRAB_BMD and TRAB_A are presented in Fig. 10.

CRT_BMD had the lowest coefficient of variation, which ranged from $2 \%$ to $4 \%$. Intermediate coefficients of variation were obtained for CRT_A and TOT_A, and ranged from $12 \%$ to $16 \%$ and from $16 \%$ to $19 \%$, respectively. Slightly higher coefficients of variation were obtained for SSI_X (from 21\% to 24\%), SSI_P (from $23 \%$ to $27 \%$ ), and SSI_Y (from $23.5 \%$ to $28.5 \%$ ). The highest coefficient of variation was obtained for TRAB_A (from $25 \%$ to $31 \%$ ). These parameters had fairly fixed coefficients of variation at each section. On the other hand, TRAB_BMD showed high variability of the coefficient of variation at each section. At the $10 \%$, $70 \%$, and $80 \%$ sections, the coefficient of variation ranged from $11 \%$ to $19 \%$. However, at the $60 \%$ section, it amounted to $30 \%$, and at the $20 \%$ section, it reached $56 \%$.

\section{Discussion}

The study focused on analysing the densitometric and geometric parameters of the third metacarpal bone in cold-blooded horses depending on the measurement site along the long axis. The division of the MCIII into sections was based on the sections proposed by Les et al. (15).

The diversity of the densitometric and geometric bone parameters depending on the bone site was studied mainly in people $(25,29)$. A statistically significant difference in the bone mineral density of the tibia was found in women. In that study, tomographic slices were analysed in four distinct cortical regions: the anterior, posterior, medial, and lateral cortical wall. The authors found that the highest values were obtained in the posterior cortical region of the tibial diaphysis (13). Similar studies were carried out in animals, particularly analysing limb long bones. Initially, they focused on examining the differences in strength parameters in a given bone depending on the site of measurement. In studies analysing isolated long bones in horses, the strength analysis was usually carried out by applying a given force $(11,15,21,23)$.

In other studies, densitometric parameters $(12,22$, $30)$ and cortical bone strength $(15,28)$ in the MCIII in horses were examined. Les et al. (15) carried out an analysis of the biomechanical properties of the cortical bone isolated from the MCIII. The bone samples from five proximodistal levels of MCIII were milled into right cylinders and compressed at the strain rate. Additionally, the dorsal, palmar, lateral, and medial areas were analysed at each level. Each sample was tested using a universal testing machine. The authors found that the location of the cortical bone along the long axis of the MCIII had a significant impact on its strength (15). In recent years, a new approach has been introduced, with the bone parameters of limbs in horses evaluated depending on the bone sections using pQCT. Studies using this method were performed on the radius and tibia in the horse. Each bone was scanned at 5\% intervals along its entire length (17). Similar studies were carried out on the hock (5). The advantage of the pQCT method is that it enables the measurement of not only the densitometric properties but also geometric parameters of the cortical and trabecular bone at particular bone sections. The latter parameters essentially determine the bone strength $(1,2)$.

Using the pQCT method, we were able to determine the expected bone strength by defining the geometric indices of bone strength of the MCIII. Peripheral quantitative computed tomography is a noninvasive imaging modality, which is based on the 
assumption that the properties of cortical bone, particularly the mineral density and cortical distribution in the cross-sectional circumference in long bones, determine the bone strength (9). First, we established the flexural and polar motions of inertia, which characterise the geometrical cross-sectional shape relative to the three-dimensional coordinate system and pass through the geometric centre of the bone. In order to calculate the SSI, the software uses the computer tomographically calculated volumetric bone mineral density (vBMD) and bone radius $(5,25)$. The use of pQCT method, based on the assumption by Feretti et al. (9), was useful in establishing the indicators of the predicted resistance to fracture. Those included the strength strain index $\mathrm{X}$ (SSI_X) $\mathrm{mm}^{3}$ - a parameter of the fracture resistance of bones in the transverse plane (forward-backward), strength strain index Y (SSI_Y) $\mathrm{mm}^{3}$ - a parameter of the fracture resistance of bones in the transverse plane to the sides, and the polar strength strain index (SSI_P) $\mathrm{mm}^{3}$ - a parameter of the transverse and torsional fracture resistance of bones.

Our analysis showed that the predicted MCIII resistance to fracture in the transverse back-front plane is the largest at $10 \%$ of the bone length, which is at the proximal metaphysis. The diaphysis region was characterised by a much lower resistance to fracture, while the distal metaphysis showed the least resistance to fracture. The largest predicted MCIII resistance to fracture in the transverse lateral - medial plane was present in the distal metaphysis. The sections in the proximal metaphysis and diaphysis had a similar resistance, which was significantly lower compared to the distal metaphysis. A fracture is less likely to occur in the transverse lateral - medial plane than in the transverse back-front plane, and the bone is more resistant to this kind of fracture. This finding was confirmed in our results, where the highest SSI_Y value was more than $60 \%$ higher than the maximal SSI_X value. The distal diaphysis had the highest predicted MCIII resistance to torsional fractures, which was two times larger than the SSI_X.

Les et al. (15) showed that the MC III cortical bone in the diaphyseal region was stiffer, stronger, and deformed less to yield and failure, and it absorbed more energy to yield than the metaphyseal cortical bone material. The authors also showed that the lateral and medial MCIII cortical bone material was stiffer and deformed less to yield and failure than the dorsal and palmar material (15). The discrepancy in our results and those of Les et al. (15) related to the maximal strength of the MCIII metaphysis and diaphysis may be caused by the fact that these authors analysed the resistance of the cortical bone to different forces than we did. Also, these authors did not take into account the geometry of the bone at its different levels. The study by Les et al. (15) analysed the resistance of cortical samples to compression along the long axis of the bone.

We also found that the predicted strength parameters are highly variable, which indicates that the
MCIII strength in horses is variable. We demonstrated that the total bone area at the TOT_A measurement site was the largest at the proximal and distal metaphysis. We also found that this parameter had a relatively high coefficient of variation, ranging from $16 \%$ to $19 \%$. This signifies that the variability of the MCIII in the studied population applies to the cross-sectional area. The largest cortical surface area at the CRT_A measurement site was present at the proximal and middle diaphysis. The coefficient of variation for this parameter ranged from $12 \%$ to $16 \%$, which indicates that the cortical surface area variation was smaller compared to the total MCIII surface area in horses. The cortical mineral density was another parameter used to assess the cortical bone at the CRT_BMD measurement site. We showed that the parameter reached statistically significant values at all the levels of the diaphysis. Similar findings were obtained in the MCIII of Arabian horses, where the bone mineral content in the diaphyseal and metaphyseal regions was compared (22). The authors found that the diaphyseal cortical BMC had higher values than the metaphyseal one. In addition, the authors of that study showed that at both bone levels, BMC values were higher in the medial aspect than in the lateral aspect. The study was carried out based on an analysis of bone optical density using adequately prepared radiograms.

We also found that of all the MCIII parameters, the CRT_BMD had the lowest coefficient of variation. Therefore, it can be concluded that the cross-sectional area and the shape of the cortical cross-section of the MCIII, and not the cortical density, have the highest variability. This may explain why the resistance to compression of cortical slices described by Les et al. (15) is the highest in the diaphysis, where we determined the highest CRT_A values. On the other hand, factors other than CTR_BMD, such as the shape and surface area of the entire MCIII bone, including the cortical bone, affect the resistance of the bone to transverse and torsional fractures.

The parameters of the trabecular bone, such as the mineral density at the TRAB_BMD measurement site and the surface area at the TRAB_A measurement site, reached the highest values at the proximal and distal metaphysis. We also showed that the cross-sectional trabecular area, similarly to the cortical area, had very high variability in horses. The density of the trabecular bone at the $10 \%, 70 \%$, and $80 \%$ cross-sections, in the proximal and distal metaphyseal regions, had little variability. The largest trabecular bone variability was at the border with the cortical bone (20\% cross-section), where it was present in some horses and was absent in others.

Conflict of Interests Statement: The authors declare that there is no conflict of interests regarding the publication of this article.

Financial Disclosure Statement: This study was supported by funds from the Department of 
Morphological Sciences, subject: "Morphology of the mammals and domestic and wild birds".

Animal Rights Statement: None required.

\section{References}

1. Alho A.: Mineral and mechanics of bone fragility fractures: A review of fixation methods. Acta Orthop Scand 1993, 64, 227-232.

2. Claes L.E., Wilke H.J., Kiefer H.: Osteonal structure better predicts tensile strength of healin bone than volume fraction. J Biomech 1995, 28, 1377-1390.

3. Currey J.D.: The effects of strain rate, reconstruction and mineral content on some mechanical properties of bovine bone. J Biomech 1975, 8, 81-86.

4. Dzierzęcka M., Charuta A.: Bone mineral density and bone mineral content of the bilateral first phalanges of the thoracic limbs in horses. Pol J Vet Sci 2012, 15, 159-161.

5. Dzierzęcka M., Charuta A.: The analysis of densitometric and geometric parameters of bilateral proximal phalanges in horses with the use of peripheral quantitative computed tomography. Acta Vet. Scand 2012, 54, 41-51.

6. Dzierzęcka M., Komosa M.: Variability of the proximal phalanx in warmblood and coldblood horses - morphological and structural analyses. Belg J Zool 2013, 143, 119-130.

7. Dzierzęcka M., Purzyc H., Charuta A., Barszcz K., Komosa M., Hecold M., Kłosińska D.: Evaluation of distal phalanx formation and association with front hoof conformation in coldblooded horses. Biologia 2016, 71, 337-342.

8. Evans R.K., Negus C., Antczak A.J., Yanovich R., Israeli E., Moran D.S.: Sex differences in parameters of bone strength in new recruits: beyond bone density. Med Sci Sports Exerc 2008, 40, 645-653.

9. Ferretti J.L., Capozza R.F., Zanchetta J.R.: Mechanical validation of a tomographic (pQCT) index for noninvasive estimation of rat femur bending strength. Bone 1996, 18, 97-102.

10. Fürst A., Meier D., Michel S., Schmidlin, A., Held L., Laib A.: Effect of age on bone mineral density and micro architecture in the radius and tibia of horses: an Xtreme computed tomographic study. BMC Vet Res 2008, 25, 1-12.

11. Gross T.S., McLeod K.J., Rubin C.T.: Characterizing bone strain distributions in vivo using three triple rosette strain gages. J Biomech 1992, 25, 1081-1087.

12. Hanson P.D., Markel M.D.: Bone mineral density measurements of equine metacarpi. Proc Am Coll Vet Surgeons 1993, 28, 13.

13. Lai Y.M., Qin L., Hung V.W., Chan K.M.: Regional differences in cortical bone mineral density in the weight-bearing long bone shaft-a pQCT study. Bone, 2005, 36, 465-471.

14. Laskey M.A., de Bono S., Zhu D., Shaw C.N., Laskey P.J., Ward K.A., Prentice A.: Evidence for enhanced characterization of cortical bone using novel pQCT shape software. J Clin Densitom 2010, 13, 247-255

15. Les C.M., Stover S.M., Keyak J.H., Taylor K.T., Willits N.H.: The distribution of material properties in the equine third metacarpal bone serves to enhance sagittal bending. J Biomech 1997, 30, 355-361.

16. Liew A.S., Johnson J.A., Patterson S.D., King G.J., Chess D.G. Effect of screw placement on fixation in the humeral head. J Shoulder Elbow Surg 2000, 9, 423-426.

17. Nicholson C.L., Firth E.C.: Assessment of bone response to conditioning exercise in the radius and tibia of young thoroughbred horses using pQCT. J Musculoskelet Neuronal Interact 2010, 10, 199-206.

18. Parkin T.D., Clegg P.D., French N.P., Proudman C.J., Riggs C.M., Singer E.R., Webbon P.M., Morgan K.L.: Horse-level risk factors for fatal distal limb fracture in racing Thoroughbreds in the UK. Equine Vet J 2004, 36, 513-519.

19. Parkin T.D., Clegg P.D., French N.P., Proudman C.J., Riggs C.M., Singer E.R., Webbon P.M., Morgan K.L.: Catastrophic fracture of the lateral condyle of the third metacarpus/metatarsus in UK racehorses - fracture descriptions and pre-existing pathology. Vet J 2006, 171, 157-165.

20. Paśko S., Dzierzęcka M., Purzyc H., Charuta A., Barszcz K., Bartyzel B.J., Komosa M.: The osteometry of equine third phalanx by the use of three-dimensional scanning: new measurement possibilities. Scanning 2017, doi:10.1155/2017/1378947.

21. Piskoty G., Jäggin S., Michel S.A., Weisse B., Terrasi G.P., Fürst A.: Resistance of equine tibiae and radii to side impact loads. Equine Vet J 2012, 44, 714-720.

22. Porr C.A., Kronfeld D.S., Lawrence L.A., Pleasant R.S., Harris P.A.: Deconditioning reduces mineral content of the third metacarpal bone in horses. J Anim Sci 1998, 76, 1875-1879.

23. Rubin C.T., Lanyon L.E.: Limb mechanics as a function of speed and gait: a study of functional strains in the radius and tibia of horse and dog. J Exp Biol 1982, 101, 187-211.

24. Skedros J.G., Sybrowsky C.L., Parry T.R., Bloebaum R.D.: Regional differences in cortical bone organization and microdamage prevalence in Rocky Mountain mule deer. Anat Rec A Discov Mol Cell Evol Biol 2003, 274, 837-850.

25. Smock A.J., Hughes J.M., Popp K L., Wetzsteon R.J., Stovitz S.D., Kaufman B.C., Kurzer M.S., Petit M.A.: Bone volumetric density, geometry, and strength in female and male collegiate runners. Med Sci Sports Exerc 2009, 41, 2026-2032.

26. Steudel K.: The work and energetic cost of locomotion. I. The effects of limb mass distribution in quadrupeds. J Exp Biol 1990, 154, 273-285.

27. Steudel K.: The work and energetic cost of locomotion. II. Partitioning the cost of internal and external work within a species. J Exp Biol 1990, 154, 287-303.

28. Stover S.M., Pool R.R., Martin R.B., Morgan J.P.: Histological features of the dorsal cortex of the third metacarpal bone middiaphysis during postnatal growth in thoroughbred horses. J Anat 1992, 181, 455-469.

29. Taes Y., Lapauw B., Griet V., De Bacquer D., Goemaere S., Zmierczak H., Kaufman J.M.: Prevalent fractures are related to cortical bone geometry in young healthy men at age of peak bone mass. J Bone Miner Res 2010, 25, 1433-1440.

30. Tóth, P., Horváth C., Ferencz V., Nagy K., Gligor N., Szenci O., Bodó G.: Assessment of the mineral density and mineral content of the equine third metacarpal and first phalanx bone by dual energy x-ray absorptiometry. Acta Vet Hung 2010, 58, 317-329. 